\title{
Mutation analysis of components of the Mediator kinase module in MED12 mutation-negative uterine leiomyomas
}

\author{
N Mäkinen ${ }^{1}$, H-R Heinonen ${ }^{1}$, J Sjöberg ${ }^{2}$, J Taipale ${ }^{3,4}$, P Vahteristo ${ }^{1}$ and L A Aaltonen ${ }^{*, 1}$ \\ 1 Department of Medical Genetics, Genome-Scale Biology Research Program, University of Helsinki, PO Box 63, 00014 Helsinki, \\ Finland; ${ }^{2}$ Department of Obstetrics and Gynecology, Helsinki University Central Hospital, PO Box 140, 00029 Helsinki, Finland; \\ ${ }^{3}$ Genome-Scale Biology Research Program and Department of Pathology, Haartman Institute, University of Helsinki, PO Box 63, \\ 00014 Helsinki, Finland and ${ }^{4}$ Science for Life Laboratory, Department of Biosciences and Nutrition, Karolinska Institute, Stockholm, \\ Sweden
}

Background: Kinase module of Mediator complex ('CDK8 submodule') consists of four subunits: CDK8, Cyclin C, MED12, and MED13. Recently, we reported recurrent MED12 mutations in 70\% of uterine leiomyomas. The aim of this study was to analyse whether mutations in other components of the module contribute to the development of these lesions.

Methods: Mutation screening of altogether 70 MED12 mutation-negative uterine leiomyomas was carried out by direct sequencing.

Results: None of the tumours displayed somatic mutations in the coding regions of CDK8/CDK19, CCNC, or MED13.

Conclusions: Mutations in CDK8/CDK19, CCNC, and MED13 do not frequently contribute to genesis of uterine leiomyomas.

Mediator is an evolutionarily conserved multi-protein complex which functions as an interface between gene-specific transcription factors and RNA polymerase II (Borggrefe and Yue, 2011). The complex is composed of three core domains (head, middle, and tail) and a distinct, less strongly associated module (the CDK8 submodule) consisting of four subunits: CDK8, Cyclin C, MED12, and MED13 (Borggrefe et al, 2002; Samuelsen et al, 2003). Mediator can be present in a cell in two different conformations. The smaller, core Mediator (S Mediator) stimulates basal transcription (Mittler et al, 2001; Baek et al, 2002). The larger form of Mediator (L Mediator), including CDK8 submodule, associates with decreased gene transcription (Knuesel et al, 2009a). The binding of the submodule causes a structural change within Mediator that prevents interactions with RNA polymerase II (Elmlund et al, 2006).

Depending on the context, CDK8 submodule itself can act as a negative or positive regulator of transcription. For example, CDK8/ Cyclin $\mathrm{C}$ is known to phosphorylate the $\mathrm{C}$-terminal domain of RNA polymerase II subunit before the formation of preinitiation complex, which disrupts Mediator-RNA polymerase II interaction and leads to the inhibition of transcription (Hengartner et al, 1998). CDK8/Cyclin C functions also together with MED12 as a positive regulator of several p53 target genes, including p21 (Donner et al, 2007). MED12 has a significant role in diverse developmental pathways, such as the nuclear receptor, Wnt, and Sonic Hedgehog signalling pathways (Belakavadi and Fondell, 2006; Kim et al, 2006; Zhou et al, 2006). It is also required for the activity of the CDK8 submodule (Knuesel et al, 2009b). MED13 connects the CDK8 submodule to Mediator (Knuesel et al, 2009a). In addition, several paralogues of the submodule subunits have been identified (Sato et al, 2004; Bourbon, 2008): MED12L, MED13L, and CDK19, a paralogue of CDK8, which is only conserved in vertebrates (Tsutsui et al, 2008). However, the effects of especially MED12L and MED13L on the function of CDK8 submodule or Mediator remain elusive.

We have previously reported specific somatic mutations in MED12 exon 2 in the majority of uterine leiomyomas (Mäkinen et al, 2011). All the mutations affected an evolutionary conserved 
region of the protein. No other frequently mutated genes have been described to date in these lesions (McGuire et al, 2012; Mehine et al, 2013; Mäkinen et al, 2014) highlighting the role of MED12 mutations in the genesis of uterine leiomyomas. The tumorigenesis mechanisms related to MED12 mutations, however, are still unclear. One attractive option is aberrant CDK8 submodule function, but this is not trivial to study. One way of examining the role of the CDK8 submodule in leiomyomagenesis is a thorough mutation analysis of all the subunits in tumours. Detection of even a small number of mutations would provide valuable clues to the uterine leiomyoma biology. Thus, we performed a comprehensive mutation screen covering the coding regions of $C D K 8 / C D K 19$, $C C N C$, and MED13, components of the CDK8 submodule, in MED12 mutation-negative uterine leiomyomas. The effort included sequencing of over 4000 DNA fragments.

\section{MATERIALS AND METHODS}

Subjects. The research material contained two series of fresh frozen uterine leiomyomas obtained from the Department of Obstetrics and Gynecology, Helsinki University Central Hospital, Finland. The first series of specimens ('M' samples) was collected in an anonymous manner from patients according to Finnish laws and regulations by the permission of the director of the health-care unit, and the other series included specimens ('MY' samples) from patients with an acquired informed consent. None of the samples displayed a mutation in MED12 exon 2 or in the coding regions of fumarate hydratase $(F H)$, a gene which has previously been associated with the predisposition to leiomyomas (Tomlinson et al, 2002). Altogether 70 leiomyomas from 46 patients were included in the study. The study was approved by the ethics review board of the Hospital District of Helsinki and Uusimaa, Finland.

Mutation screening. Mutation screening was carried out by direct sequencing. Oligonucleotide primers were designed with Primer3 software (http://frodo.wi.mit.edu) (Supplementary Table S1). Sequencing was performed using Big Dye Terminator v3.1 sequencing chemistry (Applied Biosystems, Foster City, CA, USA) on an ABI3730 automatic DNA Sequencer according to the manufacturer's instructions. The sequence graphs were analysed manually and with Mutation Surveyor software (SoftGenetics, State College, PA, USA). Mutation analysis was fully successful for $C D K 8$ exons 2-13 and CCNC. For CDK8 exon 1, CDK19 and MED13 97\%, 96\%, and 94\% of amplicons succeeded, respectively.

Owing to the exceptionally high GC content, the amplification conditions for CDK8 and MED13 exon 1 were modified from the Expand Long Template PCR system (Roche Diagnostics, Mannheim, Germany) and carried out in a total of $20 \mu \mathrm{l}$ reaction mix with $25 \mathrm{ng}$ genomic DNA, $10 \mathrm{~mm}$ dNTP, $10 \mathrm{~mm}$ of each primer, $3 \mathrm{U}$ enzyme mix, $10 \times \mathrm{BSA}, 100 \% \mathrm{DMSO}$, and $5 \mathrm{M}$ GC-melt reagent (Clontech, Palo Alto, CA, USA). After denaturation at $94^{\circ} \mathrm{C}$ for $2 \mathrm{~min}$, PCR was performed in 40 cycles of $94^{\circ} \mathrm{C}$ for $15 \mathrm{~s}$, $57^{\circ} \mathrm{C}$ for $45 \mathrm{~s}$, and $68^{\circ} \mathrm{C}$ for $7 \mathrm{~min}$, following final elongation at $68^{\circ} \mathrm{C}$ for $10 \mathrm{~min}$.

Somatic status of the observed coding sequence variants was verified by sequencing the corresponding normal tissue DNA each time the frequency of the variant was $<5 \%$. All of the observed common variants had been reported in public databases and were assumed to represent germline variation.

\section{RESULTS}

MED12 mutation-negative uterine leiomyomas did not display somatic mutations in the coding regions of CDK8/CDK19, CCNC,

\begin{tabular}{|c|c|c|c|c|}
\hline Gene & $\begin{array}{l}\text { Nucleotide } \\
\text { change }\end{array}$ & $\begin{array}{c}\text { Amino- } \\
\text { acid change }\end{array}$ & rs-number & $\begin{array}{c}\text { Number of } \\
\text { mutated } \\
\text { tumours }(/ 67)\end{array}$ \\
\hline \multirow[t]{7}{*}{ MED13 } & c. $354 \mathrm{G}>\mathrm{C}$ & p.L118L & rs78565795 & $2(3.0 \%)$ \\
\hline & c. $4275 A>G$ & p.K1425K & rs76432344 & $11(16.4 \%)$ \\
\hline & c. $4320 \mathrm{C}>\mathrm{T}$ & p.D1440D & rs671347 & 67 (100\%) \\
\hline & c. $4823 \mathrm{C}>\mathrm{T}$ & p.P1608L & rs151011641 & $1(1.5 \%)$ \\
\hline & c. $4848 \mathrm{G}>\mathrm{A}$ & p.T1616T & rs2278812 & 31 (46.3\%) \\
\hline & c. $4998 \mathrm{~A}>\mathrm{G}$ & p.L1666L & & $2(3.0 \%)$ \\
\hline & c. $6033 C>A$ & p.|20111 & rs145247799 & $3(4.5 \%)$ \\
\hline
\end{tabular}

or MED13 (see Supplementary Tables S2-S5 for more detailed information). A total of seven coding sequence variants, all in $M E D 13$, were observed in the study (Table 1): one nonsynonymous variant, c.4823C $>$ T, p. P1608L, which was predicted to have a neutral effect on protein, and six synonymous variants. Five of these represented already known synonymous changes and one synonymous change c.4998A > G, p.L1666L had not been previously reported. All the variants were of germline origin.

\section{DISCUSSION}

The aim of this study was to search for somatic mutations in the coding sequence of CDK8/CDK19, CCNC, and MED13 in MED12 mutation-negative uterine leiomyomas. Altogether 70 uterine leiomyomas were included in the study. No somatic mutations were observed in any of the genes studied. Seven coding sequence variants in MED13 were identified and all turned out to be present in the germline. These variants are probably neutral polymorphisms. MED13 haploinsufficiency has recently been suggested to underlie cataract, hearing loss, and semicircular canal dysplasia in one patient (Boutry-Kryza et al, 2012). The loss of one MED13 copy in the patient was due to an $800 \mathrm{~kb}$ deletion involving six genes in the $17 \mathrm{q} 23.2$ region.

Both $C D K 8$ and $C C N C$ are frequently dysregulated in a variety of human cancers. CDK8 has been indicated to function as an oncoprotein that promotes the proliferation of both colorectal and melanoma cancer cells (Firestein et al, 2008; Kapoor et al, 2010). Also a role as a tumour suppressor due to a loss or reduction of the protein has been reported, for example, in endometrial cancer (Gu et al, 2013). Similarly, Cyclin C has been shown to have a role both as an oncoprotein and a tumour suppressor (Xu and Ji, 2011). It is still unclear, what the exact functional consequences of $C D K 8$ and CCNC dysregulation are, and how they are linked to tumorigenesis. CDK19, the paralogue of CDK8, has also been associated with a human disease (Mukhopadhyay et al, 2010). A disruption in CDK19 caused by an inversion in chromosome 6 has been proposed to lead to microcephaly, congenital retinal fold, and mild mental retardation in a female patient.

In this study, we focused on exon and exon-intron boundaries of $C D K 8 / C D K 19, C C N C$, and MED13. This does not exclude the possibility that intronic variants, changes in regulatory elements, or somatic structural rearrangements in these genes contribute to leiomyomagenesis. Notably, when available gene expression data of 44 MED12 mutation-negative uterine leiomyomas was compared with that of the corresponding myometrium, nostatistically significant differences in fold change (FC>2) of CDK8/CDK19, $C C N C$, and MED13 were observed (data not shown). According to 
the literature, on the other hand, somatic structural rearrangements are known to have an impact to the development of MED12 wild-type lesions. For example, translocations, which lead to HMGA2 overexpression (Gattas et al, 1999; Gross et al, 2003), have been linked to MED12 mutation-negative leiomyomas (Markowski et al, 2012; Mehine et al, 2013). The structural rearrangements, however, do not explain the genesis of all MED12 wild-type lesions.

Taken together, our mutation screen of uterine leiomyomas did not reveal somatic coding mutations in CDK8/CDK19, CCNC, and $M E D 13$. Notably, no such mutations were observed in $M E D 12 L$ or $M E D 13 L$ either by analysing whole-genome sequencing data of 34 MED12 mutation-negative uterine leiomyomas on hand. Thus, MED12 mutations are likely to lead to specific functional effects not concurrently replicated by mutations in other components of the Mediator kinase module.

\section{ACKNOWLEDGEMENTS}

We express our gratitude to Sini Nieminen for the help with the samples, and Iina Vuoristo, Inga-Lill Svedberg, and Alison Ollikainen for technical assistance. This study was supported by the Academy of Finland (Center of Excellence in Cancer Genetics Research, 250345, and PV 260370), the Sigrid Jusélius Foundation (LAA, PV), and the Cancer Society of Finland (LAA, PV, NM), as well as the Maud Kuistila Memorial Foundation (NM) and Biomedicum Helsinki Foundation (NM).

\section{CONFLICT OF INTEREST}

The authors declare no conflict of interest.

\section{REFERENCES}

Baek HJ, Malik S, Qin J, Roeder RG (2002) Requirement of TRAP/mediator for both activator-independent and activator-dependent transcription in conjunction with TFIID-associated TAF(II)s. Mol Cell Biol 22: 2842-2852.

Belakavadi M, Fondell JD (2006) Role of the mediator complex in nuclear hormone receptor signaling. Rev Physiol Biochem Pharmacol 156: $23-43$.

Borggrefe T, Davis R, Erdjument-Bromage H, Tempst P, Kornberg RD (2002) A complex of the Srb8, $-9,-10$, and -11 transcriptional regulatory proteins from yeast. J Biol Chem 277: 44202-44207.

Borggrefe T, Yue X (2011) Interactions between subunits of the Mediator complex with gene-specific transcription factors. Semin Cell Dev Biol 22: 759-768.

Bourbon HM (2008) Comparative genomics supports a deep evolutionary origin for the large, four-module transcriptional mediator complex. Nucleic Acids Res 36: 3993-4008.

Boutry-Kryza N, Labalme A, Till M, Schluth-Bolard C, Langue J, Turleau C, Edery P, Sanlaville D (2012) An $800 \mathrm{~kb}$ deletion at 17q23.2 including the MED13 (THRAP1) gene, revealed by aCGH in a patient with a SMC 17p. Am J Med Genet A 158A: 400-405.

Donner AJ, Szostek S, Hoover JM, Espinosa JM (2007) CDK8 is a stimulus-specific positive coregulator of p53 target genes. Mol Cell 27: 121-133.

Elmlund H, Baraznenok V, Lindahl M, Samuelsen CO, Koeck PJ, Holmberg S, Hebert H, Gustafsson CM (2006) The cyclin-dependent kinase 8 module sterically blocks Mediator interactions with RNA polymerase II. Proc Natl Acad Sci USA 103: 15788-15793.

Firestein R, Bass AJ, Kim SY, Dunn IF, Silver SJ, Guney I, Freed E, Ligon AH, Vena N, Ogino S, Chheda MG, Tamayo P, Finn S, Shrestha Y, Boehm JS, Jain S, Bojarski E, Mermel C, Barretina J, Chan JA, Baselga J, Tabernero J, Root DE, Fuchs CS, Loda M, Shivdasani RA, Meyerson M, Hahn WC
(2008) CDK8 is a colorectal cancer oncogene that regulates beta-catenin activity. Nature 455: 547-551.

Gattas GJ, Quade BJ, Nowak RA, Morton CC (1999) HMGIC expression in human adult and fetal tissues and in uterine leiomyomata. Genes Chromosomes Cancer 25: 316-322.

Gross KL, Neskey DM, Manchanda N, Weremowicz S, Kleinman MS, Nowak RA, Ligon AH, Rogalla P, Drechsler K, Bullerdiek J, Morton CC (2003) HMGA2 expression in uterine leiomyomata and myometrium: quantitative analysis and tissue culture studies. Genes Chromosomes Cancer 38: 68-79.

Gu W, Wang C, Li W, Hsu FN, Tian L, Zhou J, Yuan C, Xie XJ, Jiang T, Addya S, Tai Y, Kong B, Ji JY (2013) Tumor-suppressive effects of CDK8 in endometrial cancer cells. Cell Cycle 12: 987-999.

Hengartner CJ, Myer VE, Liao SM, Wilson CJ, Koh SS, Young RA (1998) Temporal regulation of RNA polymerase II by Srb10 and Kin28 cyclin-dependent kinases. Mol Cell 2: 43-53.

Kapoor A, Goldberg MS, Cumberland LK, Ratnakumar K, Segura MF, Emanuel PO, Menendez S, Vardabasso C, Leroy G, Vidal CI, Polsky D, Osman I, Garcia BA, Hernando E, Bernstein E (2010) The histone variant macroH2A suppresses melanoma progression through regulation of CDK8. Nature 468: 1105-1109.

Kim S, Xu X, Hecht A, Boyer TG (2006) Mediator is a transducer of Wnt/beta-catenin signaling. J Biol Chem 281: 14066-14075.

Knuesel MT, Meyer KD, Bernecky C, Taatjes DJ (2009a) The human CDK8 subcomplex is a molecular switch that controls Mediator coactivator function. Genes Dev 23: 439-451.

Knuesel MT, Meyer KD, Donner AJ, Espinosa JM, Taatjes DJ (2009b) The human CDK8 subcomplex is a histone kinase that requires Med12 for activity and can function independently of mediator. Mol Cell Biol 29: 650-661.

Markowski DN, Bartnitzke S, Loning T, Drieschner N, Helmke BM, Bullerdiek J (2012) MED12 mutations in uterine fibroids-their relationship to cytogenetic subgroups. Int J Cancer 131: 1528-1536.

McGuire MM, Yatsenko A, Hoffner L, Jones M, Surti U, Rajkovic A (2012) Whole exome sequencing in a random sample of North American women with leiomyomas identifies MED12 mutations in majority of uterine leiomyomas. PLoS One 7: e33251.

Mehine M, Kaasinen E, Mäkinen N, Katainen R, Kämpjärvi K, Pitkänen E, Heinonen HR, Butzow R, Kilpivaara O, Kuosmanen A, Ristolainen H, Gentile M, Sjöberg J, Vahteristo P, Aaltonen LA (2013) Characterization of uterine leiomyomas by whole-genome sequencing. $N$ Engl J Med 369: 43-53.

Mittler G, Kremmer E, Timmers HT, Meisterernst M (2001) Novel critical role of a human Mediator complex for basal RNA polymerase II transcription. EMBO Rep 2: 808-813.

Mukhopadhyay A, Kramer JM, Merkx G, Lugtenberg D, Smeets DF, Oortveld MA, Blokland EA, Agrawal J, Schenck A, van Bokhoven H, Huys E, Schoenmakers EF, van Kessel AG, van Nouhuys CE, Cremers FP (2010) CDK19 is disrupted in a female patient with bilateral congenital retinal folds, microcephaly and mild mental retardation. Hum Genet 128: 281-291.

Mäkinen N, Mehine M, Tolvanen J, Kaasinen E, Li Y, Lehtonen HJ, Gentile M, Yan J, Enge M, Taipale M, Aavikko M, Katainen R, Virolainen E, Böhling T, Koski TA, Launonen V, Sjöberg J, Taipale J, Vahteristo P, Aaltonen LA (2011) MED12, the mediator complex subunit 12 gene, is mutated at high frequency in uterine leiomyomas. Science 334: 252-255.

Mäkinen N, Vahteristo P, Butzow R, Sjöberg J, Aaltonen LA (2014) Exomic landscape of MED12 mutation negative and positive uterine leiomyomas. Int J Cancer 134(4): 1008-1012.

Samuelsen CO, Baraznenok V, Khorosjutina O, Spahr H, Kieselbach T, Holmberg S, Gustafsson CM (2003) TRAP230/ARC240 and TRAP240/ ARC250 Mediator subunits are functionally conserved through evolution. Proc Natl Acad Sci USA 100: 6422-6427.

Sato S, Tomomori-Sato C, Parmely TJ, Florens L, Zybailov B, Swanson SK, Banks CA, Jin J, Cai Y, Washburn MP, Conaway JW, Conaway RC (2004) A set of consensus mammalian mediator subunits identified by multidimensional protein identification technology. Mol Cell 14: 685-691.

Tomlinson IP, Alam NA, Rowan AJ, Barclay E, Jaeger EE, Kelsell D, Leigh I, Gorman P, Lamlum H, Rahman S, Roylance RR, Olpin S, Bevan S, Barker K, Hearle N, Houlston RS, Kiuru M, Lehtonen R, Karhu A, Vilkki S, Laiho P, Eklund C, Vierimaa O, Aittomäki K, Hietala M, 
Sistonen P, Paetau A, Salovaara R, Herva R, Launonen V, Aaltonen LA. Multiple Leiomyoma Consortium (2002) Germline mutations in FH predispose to dominantly inherited uterine fibroids, skin leiomyomata and papillary renal cell cancer. Nat Genet 30: 406-410.

Tsutsui T, Umemura H, Tanaka A, Mizuki F, Hirose Y, Ohkuma Y (2008)

Human mediator kinase subunit CDK11 plays a negative role in viral activator VP16-dependent transcriptional regulation. Genes Cells 13: $817-826$.

Xu W, Ji JY (2011) Dysregulation of CDK8 and Cyclin C in tumorigenesis. $J$ Genet Genomics 38: 439-452.

Zhou H, Kim S, Ishii S, Boyer TG (2006) Mediator modulates Gli3-dependent Sonic hedgehog signaling. Mol Cell Biol 26: 8667-8682.

Supplementary Information accompanies this paper on British Journal of Cancer website (http://www.nature.com/bjc) 